\title{
Determinantes del tamaño de las ciudades
}

Un análisis para el caso de la provincia de Buenos Aires

Tesista: Julieta Carapelli

Director. Juan I. Zoloa 


\section{Índice}

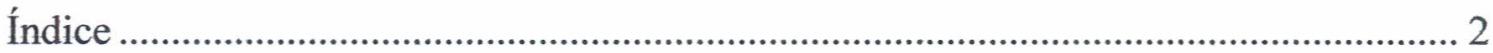

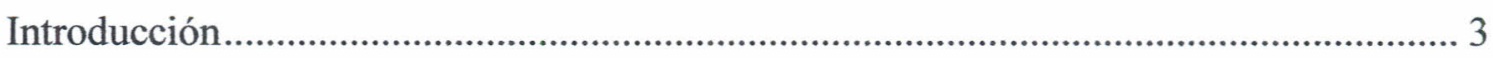

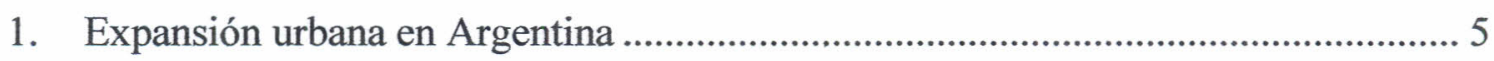

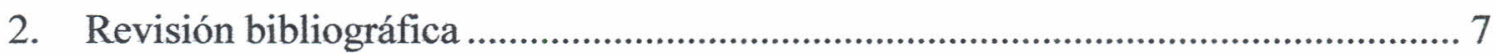

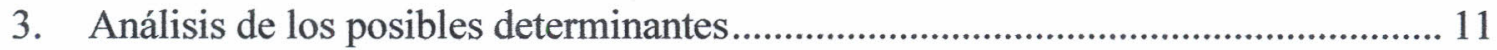

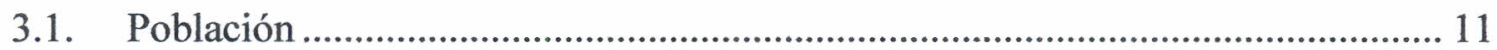

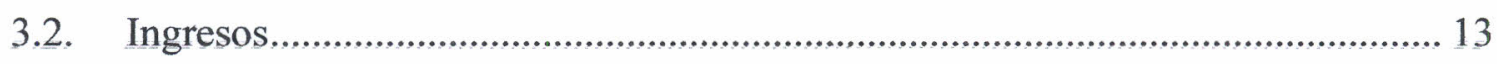

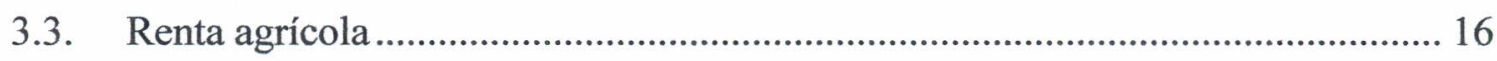

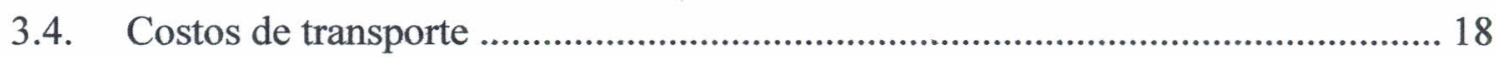

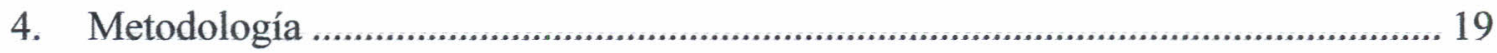

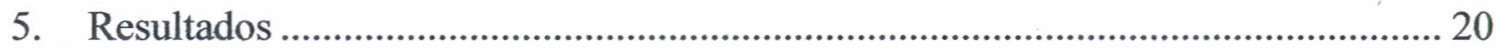

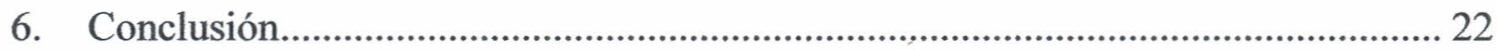

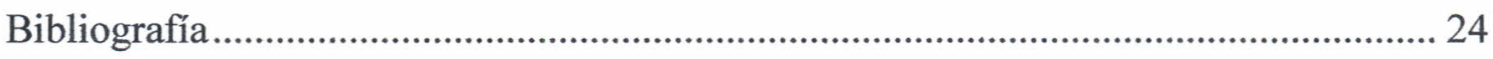

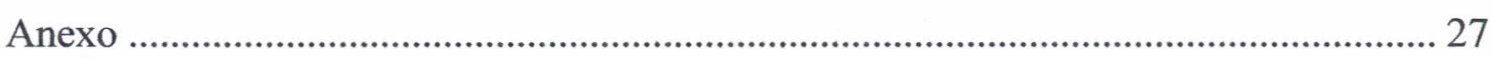

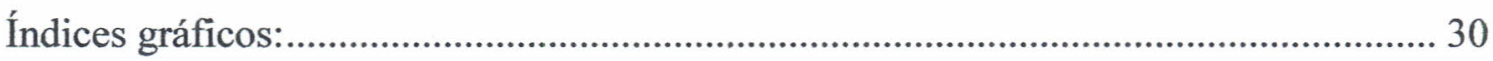




\section{Introducción}

En la actualidad, más de la mitad de la población mundial vive y trabaja en las ciudades. Las ciudades son uno de los motores del desarrollo económico y social, donde se crean oportunidades para el intercambio de conocimiento, la innovación y la cooperación.

El desarrollo urbano puede no distribuirse uniformemente a través del espacio y algunos autores enuncian los problemas que acarrea la dispersión urbana (Burchell el al, 1998; Downs, 1999; Muñiz y Galindo, 2005).

Respecto de este crecimiento no homogéneo, se ha desarrollado un fuerte concepto contra el mismo, conocido como "expansión urbana" o "urban sprawl", el cual se ha ido generando durante los últimos años. Se afirma que hay ciudades que ocupan demasiado espacio, invadiendo tierras agrícolas, lo que puede llevar a una pérdida de los beneficios estéticos de la presencia de espacios abiertos, así como el agotamiento de un recurso supuestamente escaso (campos agrícolas).

El termino urban sprawl ha resultado ser elástico en cuanto a su definición, utilizándose para definir fenómenos de expansión urbana de diferente naturaleza, y según los distintos autores que han estudiado el tema. Algunos autores lo establecen como una definición que pretende abarcar los modelos que pueden seguir un proceso de expansión urbana (Gaslter et al, 2001, Torrens y Alberti, 2000). Otros autores equiparan dispersión con suburbanización (Gordon y Wong, 1985; Glaeser y Kahn, 2004), en tantos otros trabajos se han centrado principalmente en estudiar los efectos nocivos de la dispersión, hasta el punto de incluir alguno de ellos en la propia definición (Ewing, 1997).

El excesivo crecimiento urbano puede generar otros problemas adicionales, tales como congestión del tráfico, contaminación atmosférica, disminución de espacios abiertos y reducción en los incentivo para el redesarrollo de la tierra más cercana a los centros urbanos, contribuyendo así a la decadencia de las áreas del centro y al disminuir la densidad en el centro se reduce interacción social. Además de implicar mayores costos de infraestructuras, cloacas, redes de agua potable y de todas las inversiones necesarias que requiere el crecimiento de las ciudades.

Autores como Bryant y Conklin (1975) sostienen que el fenómeno de expansión urbana, caracterizado por esta vigorosa expansión en las aéreas urbanas, es un síntoma de un sistema económico malo. Esta falla en el sistema conlleva a que se transformen granjas (o tierras agrícolas) en suburbios, alterando el balance natural entre la asignación de los usos de la tierra entre urbano y rural, conduciendo a una degradación lamentable del 
paisaje. Esta postura se traduce a menudo en políticas de zonificación que restringen la conversión de tierra agrícola a uso urbano, pudiendo aplicarse por ejemplo políticas de zonificación, que restrinjan la construcción en determinadas zonas de la periferia urbana.

Alternativamente, otra visión de la literatura urbana se encuentra en marcado contraste con lo mencionado anteriormente. Autores de esta corriente creen que el tamaño del espacio urbano está determinado por un proceso de mercado ordenado, que asigna correctamente la tierra entre los usos urbanos y agrícolas. El modelo que formaliza esta postura fue inicialmente desarrollado por Alonso (1964), Muth (1969) y Mills (1972) y más completamente analizados por Wheaton (1974). Los autores sugieren que el tamaño del espacio urbano está determinado por un conjunto de factores, entre los que se encuentran la población, los ingresos, la renta agrícola y los costos de transporte.

Asimismo, para Brueckner (2000), la competencia por la tierra entre los promotores inmobiliarios y los usuarios no urbanos (principalmente los agricultores y otros usuarios agrícolas) ayuda a determinar el tamaño espacial de las ciudades. Para que la ciudad se desarrolle espacialmente, los promotores inmobiliarios debieran ser capaces de poder ofrecer nuevas tierras, ganadas al agro en pos de la urbanización.

Esta corriente sostiene que el crecimiento urbano no es un proceso indiscriminado, que devora las tierras agrícolas sin tener en cuenta su valor. Aunque los críticos de la expansión urbana parecen tener este punto de vista del proceso de crecimiento, que no es compatible con el funcionamiento de una economía de libre mercado, donde los recursos deben encontrar sus usos más productivos. La tierra productiva agrícola es por lo tanto más resistente a la expansión urbana que tierras improductivas, lo que refleja el funcionamiento de la mano invisible.

El objetivo principal del trabajo es brindar evidencia para esta discusión del urban sprawl, como así también estudiar los determinantes de la expansión urbana, los factores explicativos del crecimiento en el tamaño de las ciudades, especialmente en el ámbito de Argentina, y en particular en la provincia de Buenos Aires.

El trabajo encuentra evidencia a favor de la asignación eficiente de las tierras por parte del mercado en su distribución entre el uso urbano y rural. Las zonas con tierras agrícolas más productivas tienden a ser tener ciudades más concentradas que las que cuentan con superficie rurales menos productivas.

El trabajo se organiza de la siguiente manera. En la primera sección se hace un análisis de la expansión urbana en la Argentina y en particular en la provincia de Buenos Aires. 
En la segunda sección se realiza una revisión bibliográfica del urban sprawl. La tercera sección consta del análisis de los posibles determinantes del tamaño de las ciudades.

En la sección cuarta se describe la metodología, mientras que en la quinta sección se exponen los resultados obtenidos y un análisis de los signos y coeficientes obtenidos.

Por último la sección sexta brinda la conclusión del trabajo.

\section{Expansión urbana en Argentina}

La expansión urbana, y más aun las causas de la misma, son temas que no han sido profundamente estudiados en la Argentina. La ciudad es un fenómeno tan evidente, natural a nuestra propia historia y civilización que pocos han tenido la necesidad de estudiarla como un fenómeno económico especifico.

La distribución espacial de la población está relacionada con distintos factores, entre ellos los atractivos económicos, sociales y culturales, los procesos de desestructuración social o crisis socioeconómicas localizadas geográficamente, habitabilidad de los ecosistemas, la conectividad de las localidades, la historia de las regiones y ciudades. Asimismo, el acceso a la propiedad de la tierra, las distintas políticas públicas que afectan directa o indirectamente a la localización de la población y los flujos migratorios de los cuales son receptoras las distintas zonas explican también la distribución espacial.

Según la última medición disponible ${ }^{1}$ la provincia de Buenos Aires se caracteriza por tener un alto grado de urbanización. El 96,4\% de su población se considera urbano. Es decir, de los 13,8 millones de habitantes que poseía la provincia en 2001, 13,3 millones de habitantes residen en zonas urbanas, consideradas como tales aquellas zonas cuya población supera los 2000 habitantes ${ }^{2}$. Cabe destacar que este nivel de urbanización no fue el mismo para todos los partidos. En particular, los partidos de General Villegas, Magdalena, General Pinto y Torquinst se encuentran por debajo del $60 \%$ de nivel de urbanización.

La población urbana en la provincia de Buenos Aires ha estado en continuo crecimiento desde el primer Censo Nacional llevado a cabo en el año 1869, en el cual el 17,5\% de la población era urbana. Desde ese entonces y hasta la última medición, los niveles de población urbana se han ido incrementando, aunque a tasas decrecientes.

\footnotetext{
${ }^{1}$ Censo Nacional de Población, Hogares y Viviendas 2001.

${ }^{2}$ La urbanización se entiende como el proceso de concentración de la población sobre la superficie de la Tierra. Según la definición clásica, elaborada por Hope Eldrige este proceso se desarrolla de dos formas: por multiplicación de puntos de concentración o mediante el aumento del tamaño de los mismos.
} 
El crecimiento de la población urbana ha tenido distintas fases a lo largo de los años. El acelerado ritmo de crecimiento puede observarse en el periodo comprendido desde el censo de 1947 hasta el del año 1980, cuando se incorporaban a la población urbana de la provincia aproximadamente 210 mil personas en promedio por año.

Tabla 1. Crecimiento intercensal, población urbana. Años censales 1869 - 2001.

\begin{tabular}{|c|c|c|}
\hline Período & Absoluto & Anual medio \\
\hline $1869-1895$ & 270.754 & 10.414 \\
\hline $1895-1914$ & 799.510 & 41.649 \\
\hline $1914-1947$ & 1.925 .133 & 57.669 \\
\hline $1960-1970$ & 2.127 .150 & 212.448 \\
\hline $1970-1980$ & 2.111 .368 & 210.139 \\
\hline $1980-1991$ & 1.864 .196 & 176.534 \\
\hline $1991-2001$ & 1.337 .532 & 127.664 \\
\hline
\end{tabular}

Fuente: Depto. Estudios Demográficos, Dirección Provincial de Estadísticas

Adicionalmente, un indicador que permite evaluar la distribución de la población es la relación urbano - rural, medido como el número de personas que vive en zonas urbanas por cada una que habita en la zona rural. Para el caso de la provincia de Buenos Aires, esta relación es creciente en el tiempo, y se ubica en un valor de 26,5 según datos del Censo 2001. Puede observarse que solo en los dos primeros periodos censales la urbanización del país superaba levemente a la de la Provincia. Desde 1914 la relación se ha invertido y se observa la acelerada urbanización provincial desde 1947 duplicando y triplicando el valor nacional hasta la actualidad.

Tabla 2. Relación Urbano - Rural. Años censales 1869-2011

\begin{tabular}{|c|c|c|}
\hline \multirow{2}{*}{ Año Censal } & \multicolumn{2}{|c|}{ Relación Urbano/Rural } \\
\cline { 2 - 3 } & País & Pcia. Bs As \\
\hline 1869 & 0,4 & 0,2 \\
\hline 1895 & 0,6 & 0,5 \\
\hline 1914 & 1,1 & 1,2 \\
\hline 1947 & 1,6 & 2,5 \\
\hline 1960 & 2,6 & 6,7 \\
\hline 1970 & 3,8 & 10,5 \\
\hline 1980 & 4,9 & 13,6 \\
\hline 1991 & 6,8 & 19,7 \\
\hline 2001 & 8,5 & 26,5 \\
\hline
\end{tabular}

Fuente: Depto. Estudios Demográficos, Dirección Provincial de Estadísticas 
La provincia de Buenos Aires concentraba, según el Censo de Población, Hogares y Viviendas de 2001 el 38,1\% de la población total del país, por lo cual constituye un interesante objeto de estudio acerca de los determinantes del tamaño de las ciudades.

Según datos provisorios del último Censo llevado a cabo en el año 2010, la población de la provincia es de 15,6 millones de habitantes mostrando un crecimiento ínter censal de $12,8 \%$. Estos datos permiten establecer que en 2010 la provincia cuenta con el 38,9\% de la población total del país. Sin embargo, la desagregación de la población de estos últimos datos entre urbana y rural que se utiliza en este trabajo aún no está disponible.

\section{Revisión bibliográfica}

La discusión empírica comienza con el trabajo de Brueckner y Fansler (1983), donde se testea empíricamente la hipótesis de que el tamaño del espacio urbano está determinado por un proceso de mercado ordenado, que asigna correctamente la tierra entre los usos urbano y agrícola. Según estos autores el tamaño de las ciudades, medido como el área urbanizada en millas cuadradas, depende positivamente del tamaño de la población y de los ingresos, mientras que lo hacen en forma negativa de la renta agraria. Sobre los costos de transporte no encuentran evidencia concluyente.

La intuición detrás del modelo es que un incremento en la población urbana debe incrementar los límites de las ciudades, ya que más gente debe de ser alojada dentro de la misma.

Si se asume que los individuos de niveles de ingresos más altos demandan viviendas más grandes, a mayores niveles de ingreso mayor será la demanda por el espacio, lo cual hace que la ciudad se amplíe espacialmente y aumente el tamaño promedio de las viviendas. Este efecto se ve reforzado por el incentivo de los residentes de realizar sus viviendas en lugares donde estas sean más baratas o accesibles, como ser los suburbios. Contrariamente, una mayor renta agraria plantea un costo de oportunidad entre los usos asignados a las tierras, por lo que se esperan ciudades más compactas donde la tierra sea más productiva. Mayores costos de transporte disminuye la renta disponible, por lo que la demanda de viviendas lejos de los centros de las ciudades se verá reducida, conduciendo a ciudades de menor tamaño.

Lo contrario ocurriría en respuesta a una inversión en carreteras e infraestructura de transporte, debido a que estas inversiones hacen que viajar sea más rápido y más conveniente, reduciendo así el costo de los desplazamientos. Los consumidores podrían disfrutar de una vivienda barata en las afueras, mientras que pagan menos por un mayor 
trayecto. Como resultado, los suburbios parecen cada vez más atractivos cuando caen los costos de transporte y conduce a un crecimiento espacial de la ciudad. La evidencia encontrada avala las predicciones del modelo.

Otros autores, como Le Gallo y Chasco (2005), relacionan la diversidad en los tamaños de las ciudades con los procesos de industrialización y crecimiento económico llevados a cabo en España.

Munroe (2006), en su trabajo aplicado al condado de Delaware (EEUU) encuentra que los patrones de desarrollo urbano fragmentado se explican principalmente por disminuciones en los costos del desarrollo urbano debido a las mejoras en carreteras y autopistas. Asimismo, los residentes de medios y altos ingresos huyen de los males urbanos como la delincuencia y la baja calidad de las escuelas en busca de una mayor estabilidad en zonas periféricas, evitando también los costos de congestión. El crecimiento urbano y la descentralización son inevitables en una época de aumento de los ingresos y una baja de los precios agrícolas que reducen el costo de oportunidad de urbanización en la periferia urbana (Mieskowski y Mills 1993).

Edward Glaeser en su estudio respecto del tema subraya a los automotores y a su desarrollo tecnológico como uno de los principales causantes del desarrollo y expansión de las ciudades.

El modelo sostiene que los costos de transporte influyen en el grado de dispersión de dos muy maneras diferentes. En primer lugar, en el modelo monocéntrico clásico, los costos más bajos significan que las afueras de la ciudad se expanden y disminuye la densidad. Al caer los costos de trayecto, la superficie del terreno consumidos aumentan y los bordes de la ciudad de expanden. En segundo lugar, en el modelo policéntrico, el cambio de transporte publico a los automóviles reduce los costos fijos de la apertura de nuevos centros de empleos. Ya no es necesario que las empresas se establezcan cerca de las zonas habitada por los trabajadores, ni cercanos a los puertos o ferrocarriles. Adicionalmente el paso de la industria orientada a la manufactura en favor de los servicios también disminuyeron los costos fijos involucrados en la apertura de nuevos centros y el aumento de las ventajas de localización cerca de donde residía la gente.

La gran importancia de los costos de transporte en estos modelos empuja hacia la hipótesis de que el conductor final de la descentralización es el automóvil privado y sus equivalentes comerciales, incluyendo el camión.

El coche es sin duda la tecnología de transporte más importante para impactar la ciudad en los dos últimos siglos, pero está lejos de ser el único. En general, los costos de 
transporte han disminuido y esto ha permitido que el crecimiento urbano en los lugares que están alejados. Además, las innovaciones tecnológicas han permitido camiones para reemplazar a los barcos y trenes, esto es particularmente importante porque los camiones requieren mucha menos infraestructura fija de trenes y barcos.

Brueckner, en otro trabajo refiere el éxodo de la clase media desde la ciudad central a los suburbios como respuesta a la redistribución del impuesto a la renta que plantean desde el gobierno. La prestación de educación, salud publica, asistencia social y otros servicios hacia los sectores mas pobres de la zona urbana requiere por pare de los sectores de altos ingresos el pago de mayores impuesto, sean a la propiedad o a las ventas, para redistribuir a favor de los primeros. Si no se les brinda a este último grupo de individuos un beneficio desde el lado del consumo, la clase media tendrá in incentivo fiscal para migrar a una comunidad en la zona suburbana en donde la carga tributaria sea menor y los servicios públicos más abundantes.

Una confirmación empírica de este incentivo fue proporcionada por Bradfor y kelejian $(1973)^{3}$, quienes mostraron que el grado de descentralización de la población rica en un área urbana estaba positivamente influenciado por la ventaja fiscal neta que disfrutan los suburbios.

Brueckner amplia el desarrollo de esa idea con un modelo de redistribución del ingreso desde la ciudad central hacia los suburbios o zonas suburbanas. En este modelo, la tasa de migración de los ricos hacia los suburbios depende solo de la diferencia entre los ingresos entre ambas zonas después del impuesto. Es una modelo puramente fiscal, en donde el gobierno central se involucra en el comportamiento optimizador, eligiendo su política de maximización del bienestar intertemporal de los pobres teniendo en cuenta la penalización a los sectores de mayores ingresos mediante el cobro de impuestos. Este modelo captura el dilema de la redistribución del ingreso, buscando la política fiscal intertemporal óptima. Esta política puede erosionar la base imponible mediante la estimulación hacia la migración a los suburbios, o como lo menciona el autor, estimulación del vuelo hacia los mismos. Pone de manifiesto un aspecto fiscal de la crisis urbana.

Otro autor que desarrolla este aspecto fiscal del desarrollo urbano es Richard Voith. Su trabajo se refiere a los Estados Unidos, y como las políticas de financiación y venta de las propiedades afectan el desarrollo de los patrones metropolitanos. Refiere, que la

\footnotetext{
${ }^{3}$ Bradford, David and Harry Kelejian, 1973, An econometric model of the flight to the suburbs, Journal of Political Economy Xl, 566-589.
} 
mayoría de los observadores de los EE.UU. con su desarrollo metropolitano, de baja densidad y concentración de hogares de bajos ingresos en el centro, suponen que el patrón es simplemente el resultado de las preferencias de los estadounidenses por el espacio abierto, mayores tierras y cambios en los medios de transporte y comunicaciones. Pero sin embargo este patrón puede reflejar las ventajas fiscales de las propiedades ocupadas por viviendas. Las políticas publicas, en lugar de solamente los gustos de la gente, han dado lugar al patrón de desarrollo estadounidense.

Las exenciones y deducciones fiscales, a los grandes contribuyentes ayudan a mantener la demanda de viviendas, de espacios grandes. La eliminación de estas ventajas, bajaría estos niveles de demanda, resultando en un exceso de oferta de las mismas. Esto último se traduciría en la disminución de los valores de las casas hasta el crecimiento nuevamente de la demanda y el restablecimiento del equilibrio entre ambas fuerzas del mercado.

Adicionalmente, el tratamiento fiscal afecta los incentivos de las comunidades respecto a su disposición de servicios públicos y la adopción de políticas de zonificación, que separan las zonas con familias de bajos y altos ingresos.

Las deducciones impositivas tienden a magnificar el impacto de las otras fuerzas económicas que conducen a la descentralización y clasificación geográfica de los ingresos.

Los subsidios o las diversas ventajas fiscales a la vivienda aumenta directamente la cantidad de tierras que las familias desean consumir, y cuando hay zonificación, aumentan las probabilidades de que la gente de altos y bajos ingresos elijan comunidades separas para vivir.

En definitiva, Voith argumenta que a través de la deducción de intereses hipotecarios del hogar, el gobierno ha subsidiado el consumo de la vivienda y que esto ha inducido a la gente a consumir más viviendas y como consecuencia viven fuera de las áreas urbanas.

Cabe aclarar que en este trabajo de tesis, este aspecto fiscal no fue considerado ni ampliado específicamente, se baso con más detalle sobre otro tipo de determinantes del tamaño de las ciudades. Lo que no implica dejar de reconocer la importancia del mismo y el desarrollo de esta corriente, basados fundamentalmente en el modelo de Tiebuot y su teoría del voto con los pies. 
La falta de evidencia contundente a favor de alguna de las corrientes mencionadas anteriormente motiva este trabajo, el cual brinda un aporte a la discusión mediante el análisis del caso argentino.

\section{Análisis de los posibles determinantes}

Los posibles factores que determinan el tamaño de las ciudades se pueden agrupar en cuatro grupos: la población, los ingresos, la renta agrícola y los costos de transporte. Estos posibles determinantes se analizarán a continuación.

\subsection{Población}

El tamaño de la población urbana es uno de los posibles motores del desplazamiento de los límites de las ciudades, ya que más gente debe de ser alojada dentro de la misma ciudad. Los datos sobre población utilizados en este trabajo son extraídos de los Censos de Población, Hogares y Vivienda, se toma el año $2001^{4}$ por ser con el que se cuenta con información cerrada. Asimismo, este cuenta con la apertura entre población urbana y rural $^{5}$. Si bien en el año 2010 se llevo a cabo un nuevo Censo, aun no se encuentra disponible la apertura entre población urbana y rural

\footnotetext{
${ }^{4}$ Las planillas con los datos se presentan en el Anexo, en tanto los resultados se analizan en la próxima sección.

${ }^{5}$ Cabe recordar, que según las definiciones explicitadas en la metodología del censo, se denomina urbana a la población que reside en localidades de 2000 o más habitantes, población rural agrupada, a la que vive en localidades de menos de 2000 habitantes y rural dispersa a la que no vive en localidades. Las dos últimas categorías constituyen la población rural
} 
Gráfico 1: Población Urbana, provincia de Buenos Aires

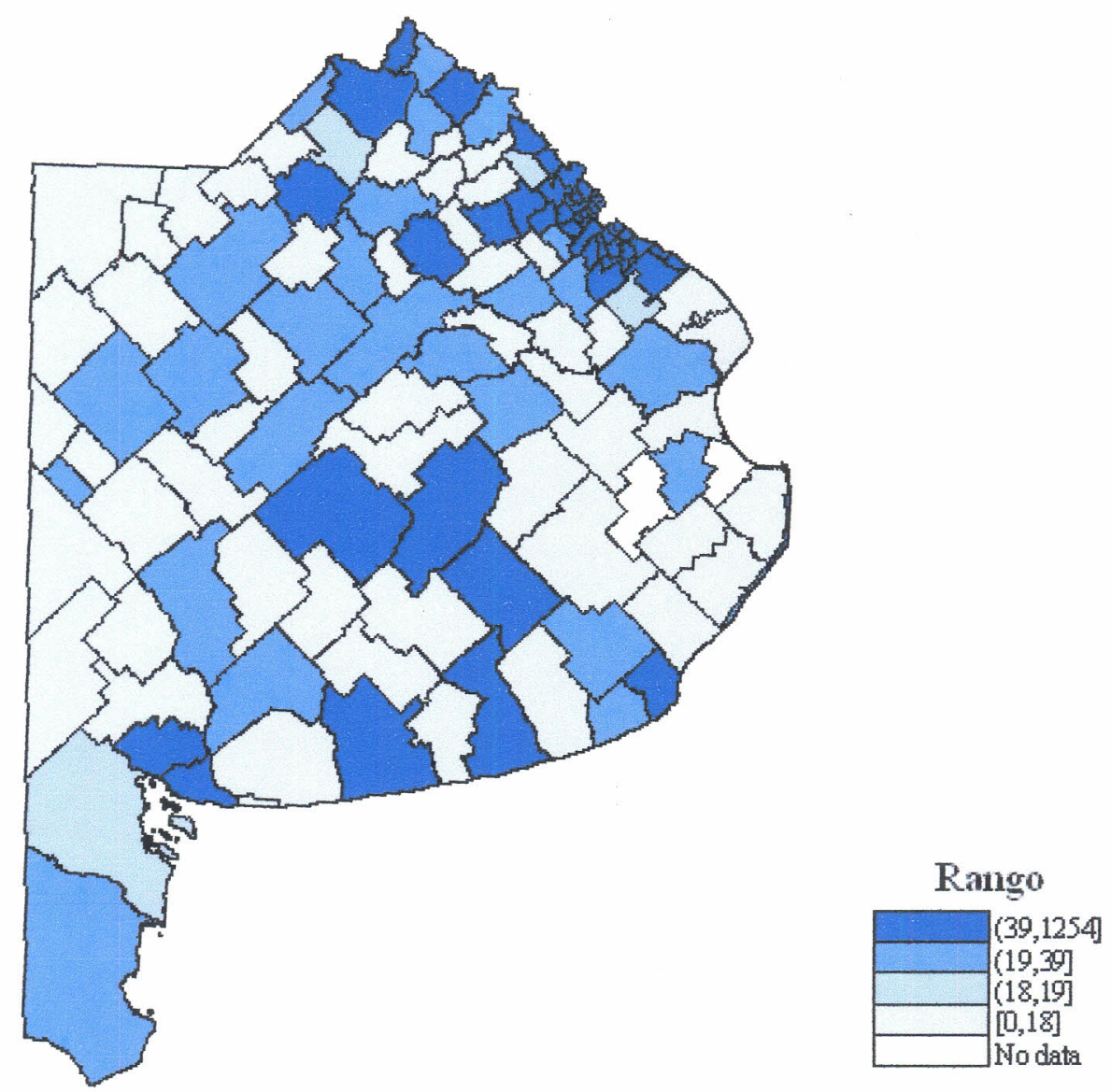

Fuente: Elaboración propia en base a datos del Censo Nacional de Población, Hogares y Viviendas, año 2001.

En el mapa precedente pueden observarse las zonas con mayor cantidad de población urbana, de donde se desprende rápidamente el conurbano bonaerense ${ }^{6}$ como la zona con mayor cantidad de habitantes. En particular, La Matanza registra el máximo valor, con un total de 1.253.921 personas, más que duplicando al partido de Lomas de Zamora, que lo secunda con 591.345 habitantes. Sobre un total de 134 partidos, solamente 27 de ellos, es decir, el $20 \%$, registran menos de 10.000 habitantes.

Otra relación complementaria a la población es la densidad poblacional, la cual mide la cantidad de habitantes por kilómetro cuadrado. Esta relación surge también de los censos. En el mapa siguiente pueden observarse los partidos más densamente poblados de la provincia, preponderando nuevamente la zona compuesta por los partidos del conurbano de la provincia, entre ellos el de mayor densidad es Lanús, con 10.068,5

\footnotetext{
${ }^{6}$ El conurbano bonaerense está integrado por 24 partidos, siendo: Almirante Brown, Avellaneda, Berazategui, Esteban Echeverría, Ezeiza, Florencio Varela, General San Martin, Hurlingham, Ituzaingo, José C Paz, La Matanza, Lanús, Lomas de Zamora, Malvinas Argentinas, Merlo, Moreno, Morón, Quilmes, San Fernando, San Isidro, San Miguel, Tigre, Tres de Febrero y Vicente López.
} 
habitantes por $\mathrm{km}^{2}$. Contrariamente, los partidos de Pila, Tordillo, General Lavalle y General Guido, poseen una densidad inferior al 1,5 habitante por $\mathrm{km}^{2}$.

Gráfico 2: Densidad de población, en habitantes por km2, provincia de Buenos Aires, Año 2001

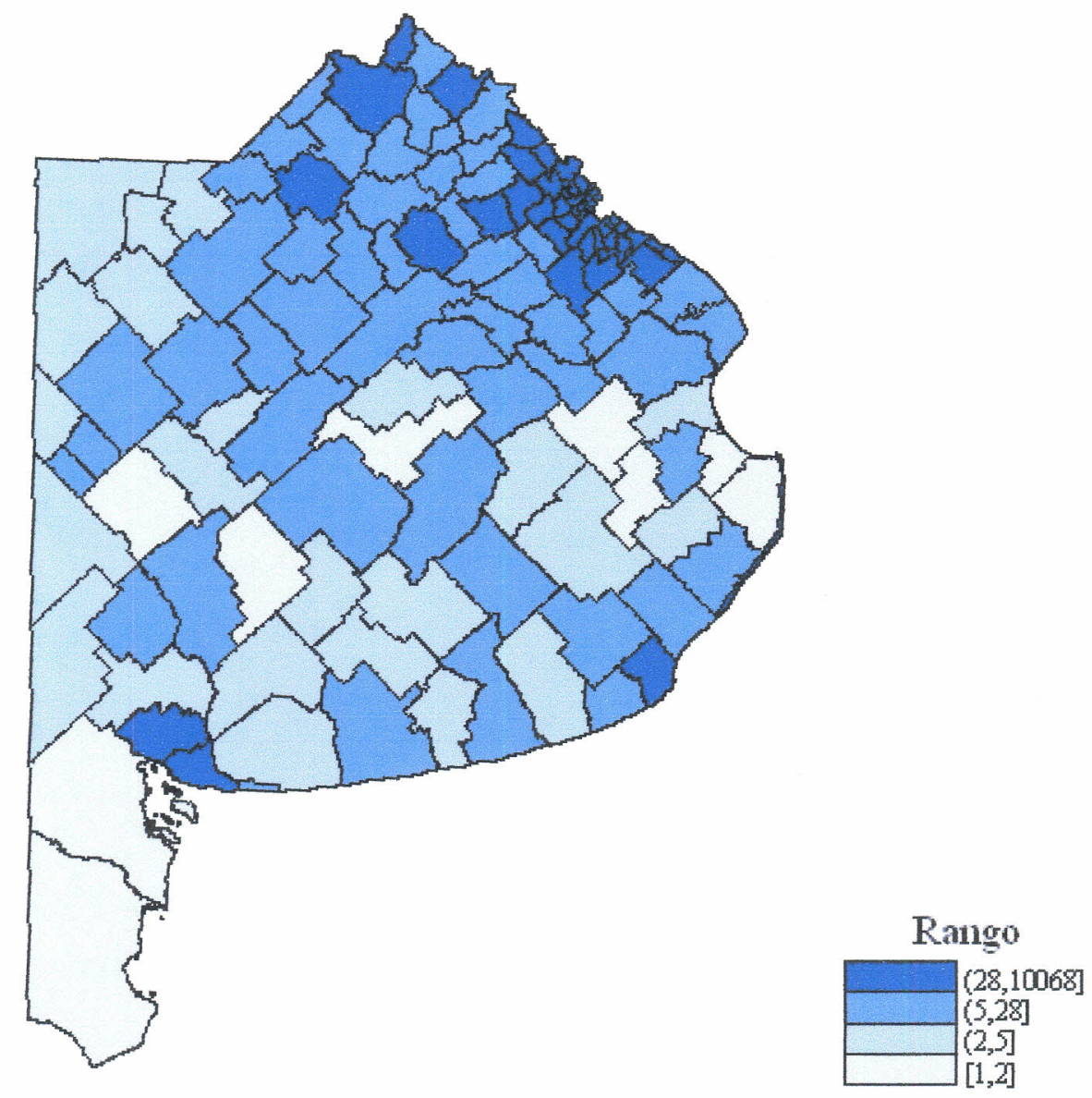

Fuente: Elaboración propia en base a datos del Censo Nacional de Población, Hogares y Viviendas, año 2001.

\subsection{Ingresos}

Los ingresos de las personas afectan las decisiones de viviendas, tanto en lo que se refiere a su tamaño como a su ubicación. Una forma de aproximar los ingresos de las localidades es a través del Producto Bruto Geográfico (PBG). Esta información es tomada de la Dirección Provincial de Estadística de la provincia de Buenos Aires (DPE).

El Producto Bruto Geográfico de una jurisdicción ${ }^{7}$ refleja la actividad económica de las unidades productivas residentes en ella, siendo igual a la suma de los valores agregados

\footnotetext{
${ }^{7}$ La delimitación de las jurisdicciones relevantes para la determinación del territorio económico se basa en las fronteras políticas. De este modo, el territorio económico provincial coincide con los límites geográficos de la Provincia e incluye además las zonas francas y otros espacios bajo control aduanero
} 
por dichas unidades productivas. Desde el punto de vista contable, el PBG es la agregación de los saldos de la cuenta de producción de las distintas ramas de actividad.

En el siguiente mapa puede observarse la distribución del PBG en el año 2001 para la provincia. El PBG de la provincia para el año 2001 es de $\$ 87.853$ millones de pesos (pesos corrientes, a precios de productor). La ciudad de La Plata muestra el mayor PBG para el año 2001 (\$6.024 millones de pesos corrientes). En tanto, el conurbano alcanzó para el año 2001 un PBG de $\$ 47.016$ millones de pesos, representando el 52,8\% del PBG total de la provincia.

Gráfico 3: Producto Bruto Geográfico, provincia de Buenos Aires.
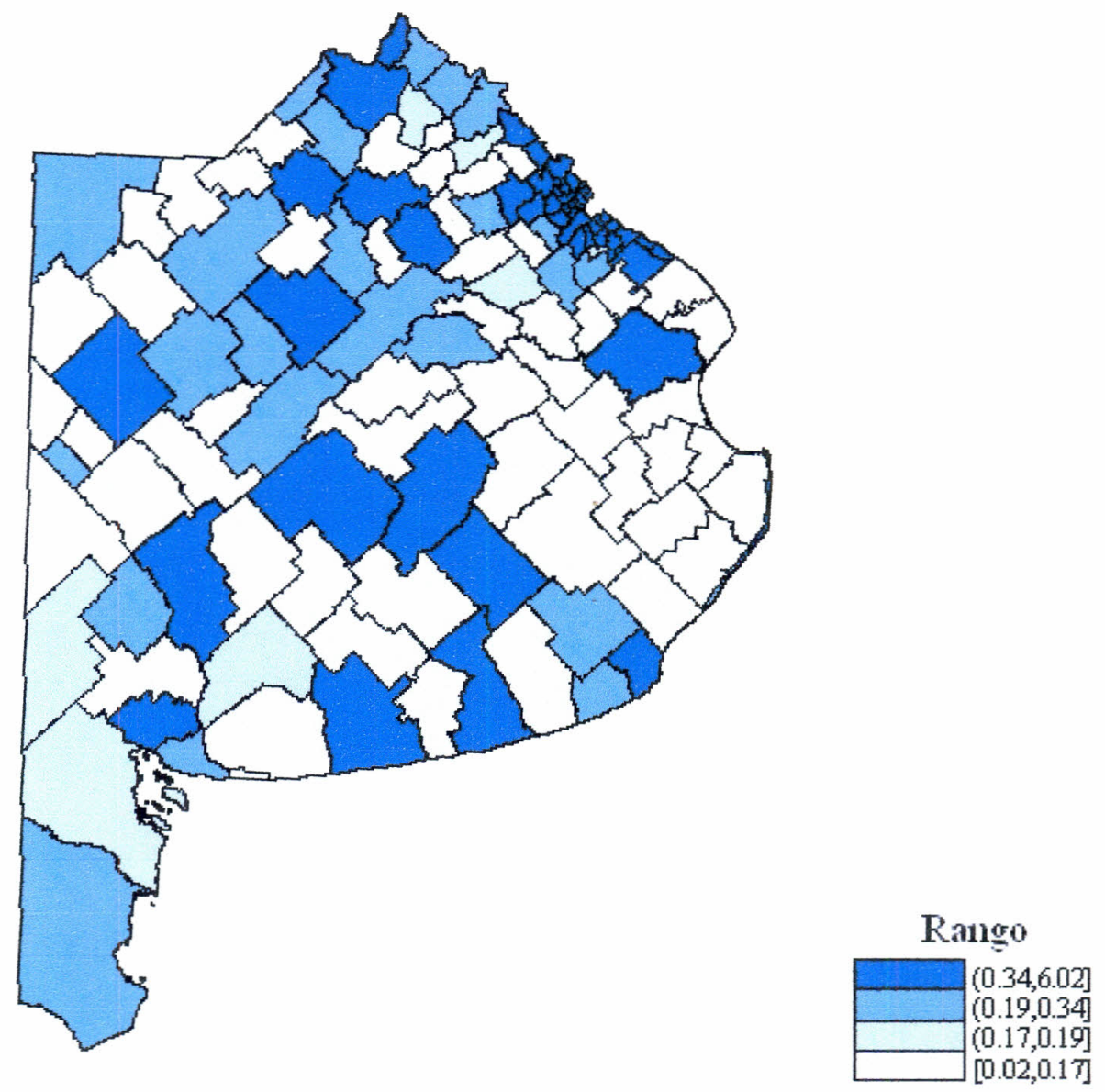

Fuente: Elaboración propia en base a datos de la DPE.

La información oficial sobre los ingresos individuales que se utiliza para medir pobreza, proviene de la Encuesta Permanente de Hogares (EPH). Lamentablemente, dicha 
encuesta solo hace referencia a 5 aglomerados de la provincia de Buenos Aires ${ }^{8}$, no cubriendo la totalidad de la provincia, dejando particularmente la zona noroeste sin datos referenciales.

Al no contar con datos sobre los ingresos individuales en cada partido, se estimo un salario horario mensual promedio por partido ${ }^{9}$. Dicha estimación es el promedio de los salarios horarios promedio por nivel educativo de los 5 aglomerados de la EPH de 2001, ponderados por la proporción de la población de cada partido que cuenta con cada nivel de instrucción formal, obtenida del Censo de 2001.

\section{Gráfico 4: Ingreso horario promedio mensual, provincia de Buenos Aires.}

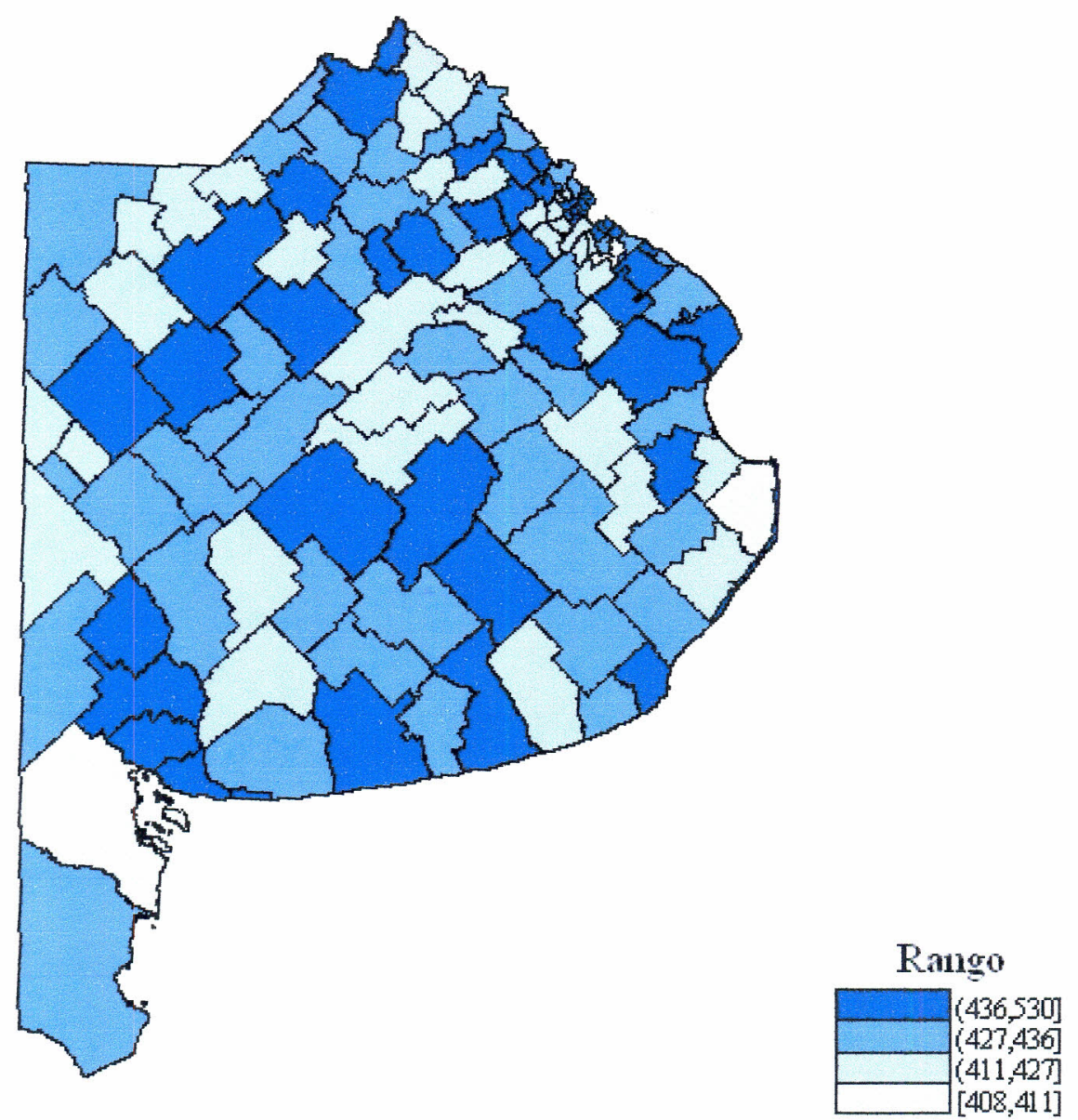

Fuente: Elaboración propia en base a datos de la EPH (2001) y del Censo Nacional de Población, Hogares y Viviendas, año 2001.

\footnotetext{
${ }^{8}$ Gran La Plata, Bahía Blanca - Cerri, Partidos del GBA, Mar del Plata - Batán y San Nicolás - Villa Constitución

${ }^{9}$ Se considero una jornada laboral de 8 horas diarias, con 20 días hábiles por mes.
} 
Con la estimación del salario individual mensual por partido se intenta asimilar los ingresos en base a los cuales los sujetos toman decisiones, entre ellas la de expandirse territorialmente. Los partidos de Vicente López y San Isidro cuentan con el nivel más alto de ingresos horario promedio de la provincia, en tanto Florencio Varela y General Lavalle muestras los de menor cuantía.

\subsection{Renta agrícola}

El costo de oportunidad asociado a los distintos usos de usos de las tierras se encuentra relacionado con la renta de la tierra agrícola.

Los precios de la tierra agrícola pueden ser aproximados por los valores expuestos en la Ley Impositiva de la provincia de Buenos Aires para el año 2010 (Ley No 14044). En la misma se detallan los valores óptimos de la tierra rural para el año 2005. Los valores óptimos reflejan el valor teórico de un campo en óptimas condiciones productivas.

Gráfico 5: Precio de la Tierra, provincia de Buenos Aires.
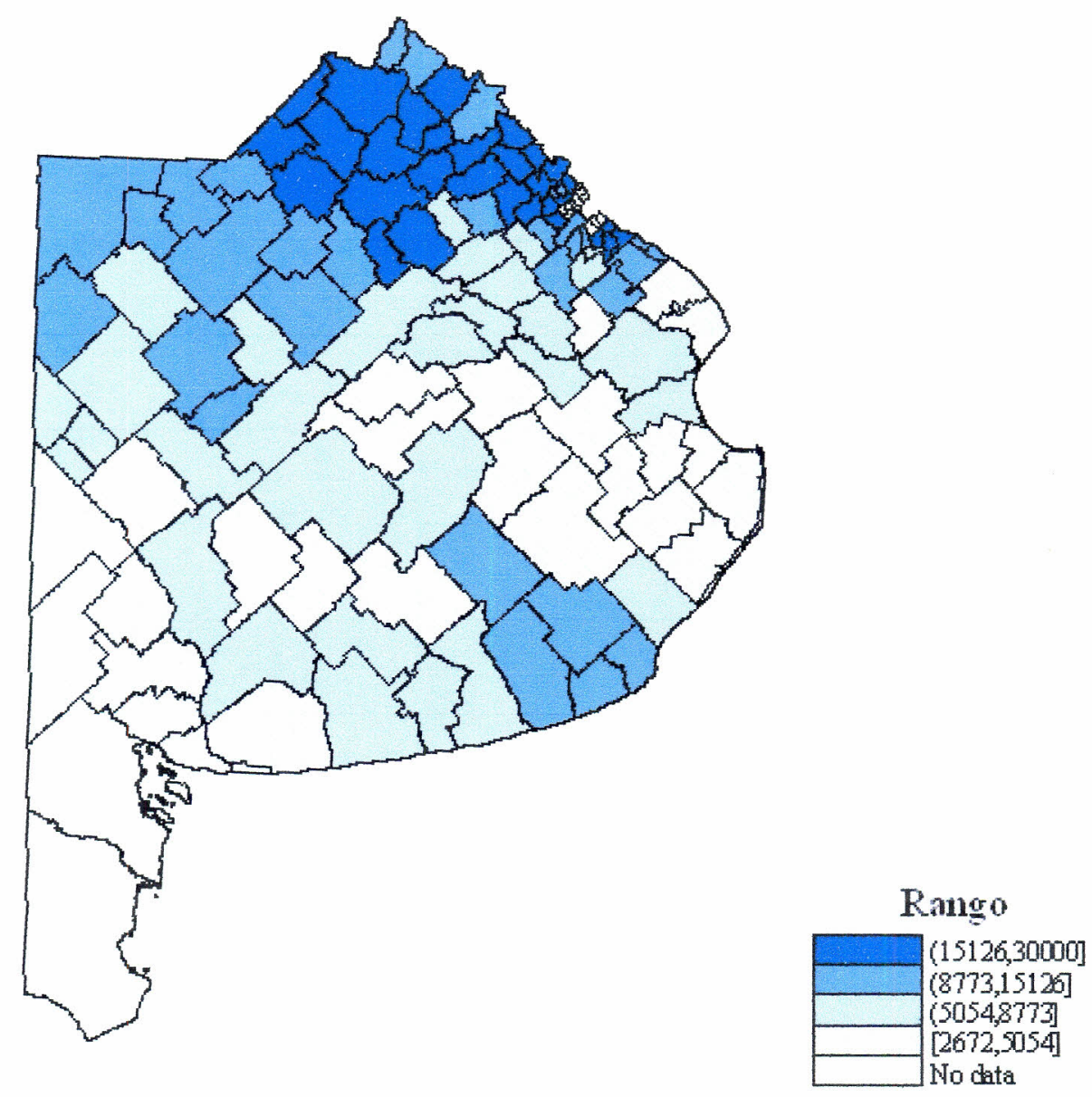

Fuente: Elaboración propia 
Las tierras con mayor valor de la provincia se encuentran ubicadas en la zona noreste de la misma. Particularmente por los partidos que conforman la zona núcleo sojera de la provincia (Pergamino, Rojas y Colon, entre otras), como asimismo las localidades pertenecientes al conurbano bonaerense (Quilmes, Pilar, Lujan y Campana entre otras). En la parte sur de la provincia las tierras que muestran los mayores valores óptimos son los partidos de Lobería, Balcarce y General Pueyrredón.

Sobre la productividad de los campos puede analizarse el Índice de Productividad de la tierra, realizado por el INTA. Dicho índice tiene en cuenta las características de los suelos, intentando reflejar en términos relativos, las características productivas de cada uno de los predios y permite establecer una valoración numérica de la capacidad productiva de las tierras, a nivel de partido.

Gráfico 6: Índice de Productividad de la Tierra, provincia de Buenos Aires.

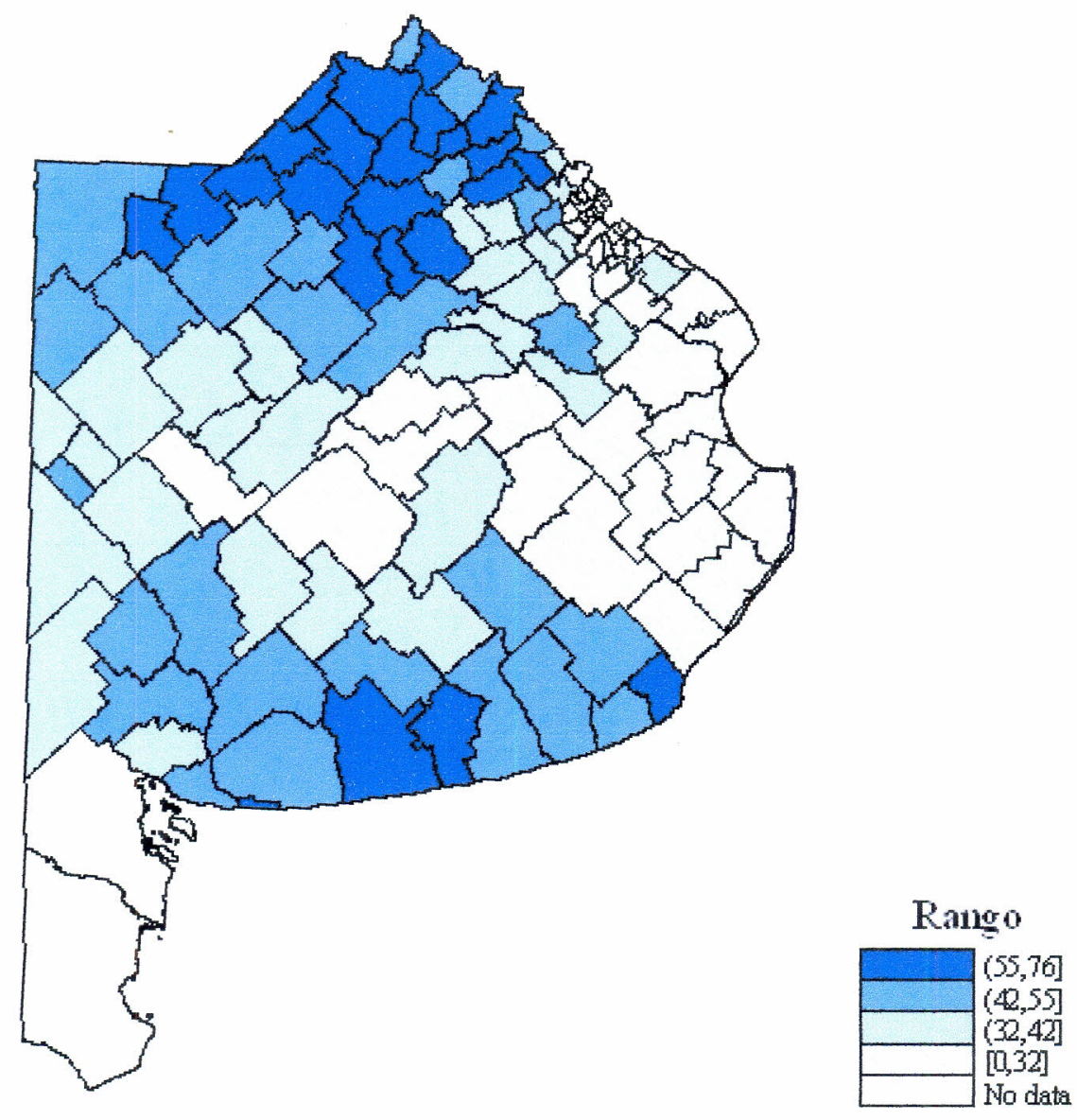

Fuente: Elaboración propia

Las tierras con el índice de productividad más alto de la provincia se encuentran en la zona norte de la misma, con el denominado núcleo sojero (Pergamino, Colon y Rojas, 
entre otros). Asimismo, en la zona sur, las tierras más productivas se encuentran en el núcleo triguero, conformado principalmente por los partidos de Necochea, Lobería y Tres Arroyos.

\subsection{Costos de transporte}

Los datos sobre los costos de transporte son escasos. No hay datos oficiales sobre el porcentaje de personas que utilizan transporte público ni sobre el porcentaje de personas propietarias de autos. Una aproximación es el Parque Automotor, dato que releva la Dirección Nacional de los Registros Nacionales de la Propiedad Automotor y de Créditos Prendarios (DNRPA). El cual indica el número de autos por localidad que cuentan con registro seccional automotor.

Gráfico 7: Parque Automotor, provincia de Buenos Aires.

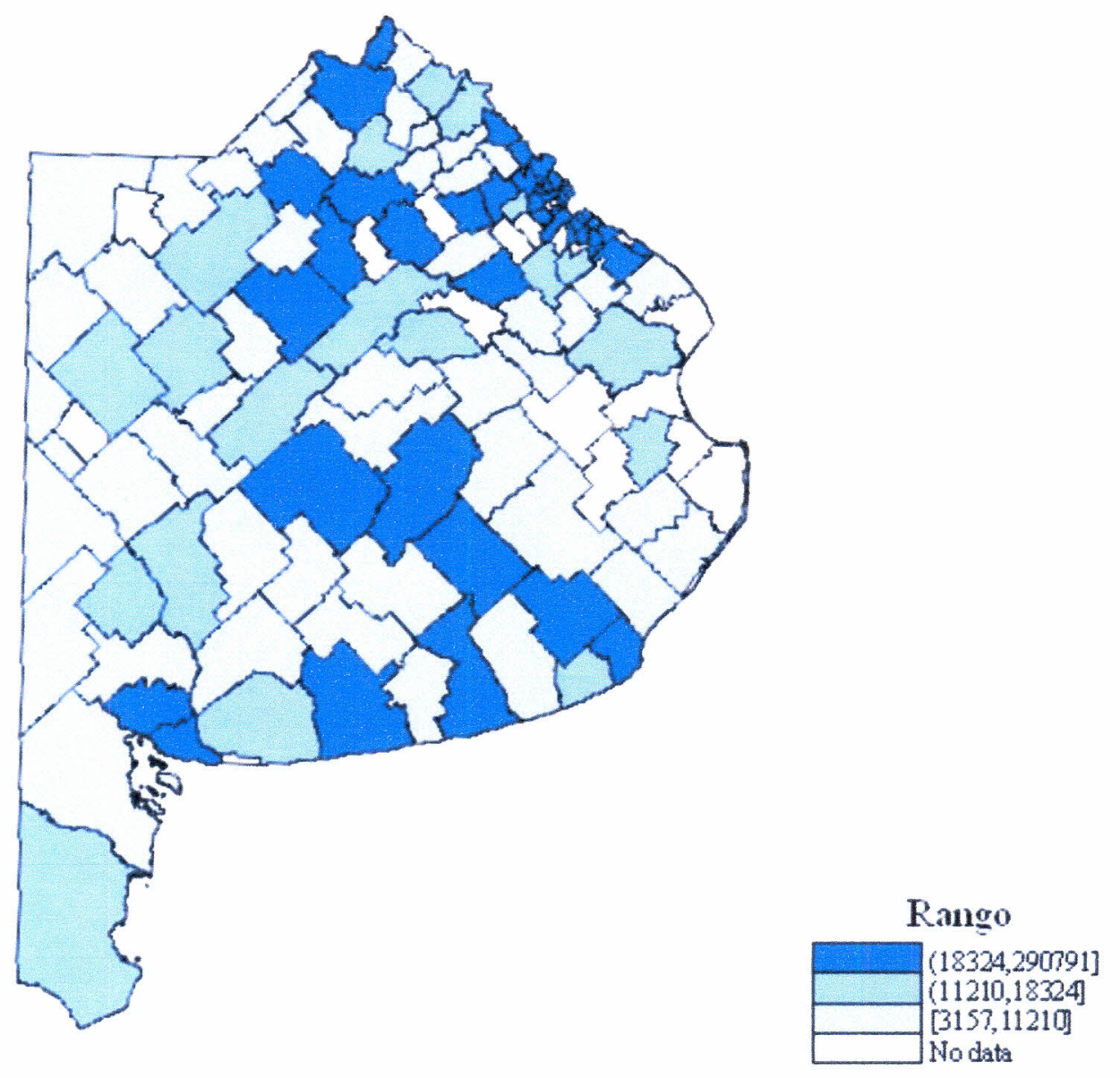

Fuente: Elaboración propia

La localidad que cuenta con mayor parque automotor es La Plata, con 290.791 autos, seguido por La Matanza, con 264.403 unidades. Los partidos de Laprida, General Pinto, 
General Alvear y Tapalqué son los partidos con menos de 3000 unidades. De los 134 partidos de la provincia, 20 de ellos no cuentan con registro seccional automotor, por lo cual no se registran datos para los mismos.

\section{Metodología}

En el trabajo se utilizan técnicas econométricas de corte transversal, a fin de testear cuales son los determinantes del tamaño de las ciudades.

Las observaciones se corresponden con los partidos que componen el territorio provincial. Dicho territorio se encuentra dividido en $134^{10}$ partidos que son, a fines estadísticos, jurisdicciones político administrativas de segundo orden.

A diferencia del modelo de Brueckner y Fansler (1983), el cual usaba la superficie de los terrenos dentro de las aéreas urbanizadas medidas en millas cuadradas, en este trabajo la variable dependiente elegida es la proporción del partido dedicada a usos urbanos de cada partido de la provincia de Buenos Aires. La misma indica la proporción de superficie considerada urbana, tanto edificada como baldía, respecto de la superficie total de la localidad.

Una dificultad que se presento al realizar este trabajo fue la falta de información para el mismo año en todas las variables utilizadas. Las variables usadas no son relevadas con periodicidad por lo cual no se encuentra disponible una serie continua y completa en el tiempo. Esto hizo que se debiera utilizar información de distintos años. Sin embargo, esto no representa un problema grave ya que la dinámica en las decisiones habitacionales no responde rápidamente ante los cambios en los factores explicativos.

\footnotetext{
${ }^{10}$ En la división político administrativa no se tiene en cuenta la posterior autonomía de Lezama, pasando a ser el partido número 135 de la provincia.
} 
El modelo a estimar es el siguiente:

Proporción Urbana $=f($ Superficie total, Población urbana, Índice de productividad, Precio de la Tierra, Parque Automotor, PGB, Wage)

donde:

Proporción Urbana: cociente entre la superficie urbana (edificada y baldía) y la superficie total del partido. Los valores se encuentran entre 0 y 100. (ARBA 2010) ${ }^{11}$. Superficie total: Superficie total del partido, en hectáreas (ARBA 2010).

Población urbana: Población que reside en cada localidad, en miles (CENSO 2001).

Índice de productividad: Valoración numérica de la capacidad productiva de la tierra. Los valores se encuentran entre 0 y 100 (INTA 2005).

Precio de la Tierra: Valor óptimo de la tierra libre de mejoras, en miles de pesos por hectárea (ARBA 2010).

Parque Automotor: Cantidad de automóviles por localidad, en miles (DNRPA 2005).

PGB: Valoración de la actividad económica de las unidades productivas de la provincia, en miles de pesos (DPE 2003).

Salario: salario horario promedio mensual por partido, en pesos. (EPH 2001).

Se decidió agregar como variable de control la superficie total del partido, dado que se está utilizando como variable dependiente una proporción. De esta manera no se estaría penalizando a los partidos con mayor superficie y quizás no tan urbanizados con respecto a otros.

Las estimaciones se realizaron con el método de Mínimo Cuadrados Ordinarios (MCO) empleando la matriz de varianzas y covarianzas de White que permite la corrección por heterocedasticidad.

\section{Resultados}

La provincia está compuesta por 134 partidos, de los cuales 92 partidos cuentan con información de todas las variables consideradas en el análisis, lo que permite cubrir

\footnotetext{
${ }^{11}$ Los valores de superficie urbana y rural fueron calculados con datos catastrales, extraídos del trabajo "El impuesto inmobiliario rural", en el marco del proyecto de cooperación técnica y académica entre la facultad de Ciencias Económicas de la UNLP y la Agencia de Recaudación de la Provincia de Buenos Aires (ARBA), para el año 2009.
} 
aproximadamente el $69 \%$ de los mismos, el $83,5 \%$ de la superficie y el $46,2 \%$ del PBG provincial.

En la siguiente tabla se exponen los resultados de la estimación.

Tabla 3. Estimación: Determinantes del tamaño de las ciudades

\begin{tabular}{|c|c|}
\hline \multicolumn{2}{|c|}{ Proporción Urbana } \\
\hline \multirow{2}{*}{ Superficie Total } & -0.045 \\
\hline & {$[0.064]$} \\
\hline \multirow{2}{*}{ Población Urbana } & $0.241 * * *$ \\
\hline & {$[0.046]$} \\
\hline \multirow{2}{*}{ PBG } & $-0.018^{* *}$ \\
\hline & {$[0.008]$} \\
\hline \multirow{2}{*}{ Salario Mensual } & $0.234 * *$ \\
\hline & [0.116] \\
\hline \multirow{2}{*}{ Precio de la Tierra } & $1.041 * * *$ \\
\hline & {$[0.293]$} \\
\hline \multirow{2}{*}{ Índice Productividad Promedio } & $-0.396^{* * *}$ \\
\hline & {$[0.109]$} \\
\hline \multirow{2}{*}{ Parque Automotor } & -0.139 \\
\hline & {$[0.160]$} \\
\hline \multirow{2}{*}{ Constante } & $-87.995 *$ \\
\hline & [50.904] \\
\hline Observations & 92 \\
\hline R-squared & 0.60 \\
\hline
\end{tabular}

El $\mathrm{R}^{2}$ ajustado es de 0,6 , es decir, las variables independientes estarían explicando un $60 \%$ de la variabilidad de la proporción urbana. En el modelo de Brueckner and Fansler el valor de $\mathrm{R}^{2}$ era de 0,77 , aunque esto no es comparable por tener variables tanto dependiente como explicativas distintas.

En cuanto a las variables independientes, son todas significativas excepto la variable de control, superficie urbana, y los costos de transporte. En tanto la variable PBG como Salario mensual son significativas al $5 \%$, mientras que el resto de las variables utilizadas (Población Urbana, Índice de Productividad promedio y precio de la tierra) presentan una significatividad del $1 \%$.

La mayoría de las variables tienen el signo esperado. La población urbana presenta signo positivo, concordante con la predicción del modelo de Brueckner. Esto indica que los partidos con mayor población urbana conllevan un mayor tamaño de la ciudad. A medida que aumenta la población de las ciudades, la misma debe de expandirse para acoger a los nuevos integrantes. Si bien es posible que pudiera darse un aumento del 
tamaño de las mismas medido en términos de crecimiento vertical, los datos con los que se cuenta no permiten verificar esta hipótesis.

Al analizar los ingresos se encuentra que el PBG presenta signo negativo y significativo, contrario al esperado. En cambio la variable que intenta captar mejor los ingresos individuales, tiene el signo positivo esperado, tendiente a reforzar la idea de que a mayores posibilidades económicas mayor será la tendencia a alejarse de los centros urbanos en busca de espacios habitacionales más amplios.

El valor óptimo de la tierra rural, que se utiliza para aproximar el precio de la tierra no presenta el signo esperado. Este valor óptimo es un valor teórico de un campo en óptimas condiciones, que puede no ser representativo de la totalidad de parcelas del partido, por lo que sus resultados deben ser analizados con cuidado.

Si en cambio se analiza la productividad promedio, que mide la capacidad productiva de la tierra, se obtiene el signo esperado. Esto refuerza la idea de que el crecimiento urbano no es un proceso anárquico que devora tierras agrícolas sin tener en cuenta su valor.

Los costos de transporte y la superficie total que actúa como variable de control no resultan significativas.

\section{Conclusión}

Dada la confluencia de una población en expansión, un aumento de los ingresos, y la caída de los costos de los desplazamientos, no es de extrañar que las ciudades se hayan expandido rápidamente en las últimas décadas. La cuestión es si esta expansión ha sido demasiado rápida, y si la mano invisible que guía la reconversión de tierras para uso urbano empuja demasiado en la dirección de las grandes ciudades.

Los resultados obtenidos corroboran que la expansión de la tierra urbana está en relación con la población, la capacidad productiva de la tierra y los salarios en la forma que predice el modelo de Brueckner. En este contexto, el impacto negativo del índice de productividad en el tamaño urbano, brinda evidencia a favor de que el tamaño del espacio urbano está determinado por un proceso de mercado ordenado, que asigna correctamente la tierra entre los usos urbanos y agrícolas.

Respecto de la población comprueba la predicción del modelo para la provincia de Buenos Aires, los partidos con mayor población urbana conllevan un mayor tamaño de la ciudad. A medida que aumenta la población de las ciudades, la misma debe de expandirse para acoger a los nuevos integrantes, expandiendo hacia afuera los bordes de las mismas. Cabe aclarar al respecto, que en este estudio no se tuvo en cuenta la 
expansión en forma vertical de las ciudades, se testeaba expansión horizontal. Es un factor que pudiera ser incorporado en una posible ampliación del trabajo.

En cuanto a los ingresos, el aumentos de los mismos lleva a que los individuos decidan alejarse de los centros urbanos, ya sea porque quieren consumir espacios más grandes destinados a vivienda, porque les sea les facilita económicamente alejarse (menores costos de transporte), o como una manera de disfrutar de las amenidades positivas que les ofrece una vida fuera de la ciudad.

Con relación a los costos de transporte, la bibliografía relevada muestra la importancia de los mismos como determinante del tamaño de las ciudades; si bien en este trabajo en particular esta variable no resulta significativa, si tiene el signo esperado. Se supone que a medida que los mismos vayan descendiendo, a los individuos se les facilita el alejamiento de los centros urbanos a favor de las zonas suburbanas.

Dentro del marco de esta expansión, pueden aparecer "fallas de mercado", como pueden ser la contaminación del aire, del agua, y hasta una contaminación visual, propias del crecimiento de la ciudad. Si este tipo de deficiencias afectan en forma negativa la calidad de vida de los individuos, podrían justificarse la adopción de las medidas necesarias para corregirlas. Sin embargo, este punto no es considerado dentro de este trabajo, quedando planteada una posible derivación para estudiar a posteriori.

Una de las limitaciones del trabajo está relacionada con la posibilidad que el crecimiento urbano se realice en forma vertical. Al no contar con datos que permitan verificar esta hipótesis, el trabajo puede estar subestimando el tamaño de las ciudades y por la tanto las estimaciones obtenidas podrían considerarse como un límite inferior de los verdaderos parámetros.

La recopilación de datos no está exenta de problemas y particularidades. Las mayores dificultades están relacionadas con los ingresos y con costos de transporte. En ambos casos el mayor problema es la ausencia de estadísticas continuas, confiables y con una apertura a nivel de partido. 


\section{Bibliografía}

Alonso, "Location and land use", Harvard University Press, 1964.

Battisti Michele - Di Vaio Gianfranco, "A spatially filtered mixture of $\beta$ - convergence regressions for EU regions, 1980-2002", 2006.

Blomm, David and Khanna Tarum, "The Urban Revolution: rapid urbanization may prove a blessing, provided the world takes notice and plans accordingly

Brueckner Jan K and David A Fansler, "The economics of urban sprawl: Theory and evidence on the spatial sizes of cities", 1982.

Brueckner Jan K., "The structure of urban equilibrium: a unfied treatment of the MuthMills model”, Handbook, 1987.

Brueckner Jan K., "Urban sprawl, diagnosis and remedies", International Regional Science Review 23, 2: 160-171, Abril 2000.

Brueckner Jan K., "Central city income redistribution and the flight to the suburbs, un modelo estilizado",1982.

Bryant and Conklin, "New farmland preservation programs in new York", Journal of the American Institute of planners 41, 1975, (390-396).

Bryant, William and Conklin," New farmland preservation program in New York", Journal of the American institute of planners 41, 1975.

Burchfield, Overman, Puga and Turner, "Causes of sprawl: a portrait from space".

Burchell, R.W., N.A. Shad, L. Listokin, H. Phillips, A. Downs, S. Seskin, J.S. Davis, T. Moore, D. Helton, M. Gall, and ECONorthwest. 1998. Costs of sprawl -revisited. Washington, DC, National Academy Press.

Downs, A, "Some realities about sprawl and urban decline". Housing Policy Debate 10:955-74. 1999.

Ewing, R. 1997. Is Los Angeles-style sprawl desirable? Journal of American Planning Association 63:107-26. 
Galster, G., R. Hanson, M. Ratcliffe, H. Wolman, and J. Freihage, "Wrestling sprawl to the ground: Defining and measuring an elusive concept". Housing Policy Debate $12: 681-717,2001$.

Glaeser Edward, "Are cities dying?" The journal of economic perspective, Vol. $12 \mathrm{~N}^{\circ} 2$ (139-160), 1998.

Glaeser, E. L., M.E. Kahn, "Sprawl and urban growth. In Handbook of Regional and Urban Economics", Volume 4, eds. J.V. Henderson, P. Nijkamp, E.S. Mills, P.C. Cheshire, and J.F. Thisse, 2481-527, Amsterdam: North Holland, 2004.

Goodman, Christopher B, "The Fiscal Impacts of Residential Land Use Characteristics".

Gordon, P., and H.L. Wong," The costs of urban sprawl -Some new evidence" Environment and Planning A 17:661-66, 1985.

Informe "Migraciones internas en la provincia de Buenos Aires", Dpto. Estudios demográficos, Dirección Provincial de Estadística.

Julie Le Gallo - Coro Chasco, "Spatial analysis of urban growth in Spain, 1900-2001", 2005.

Mieskowski P and Mills E, "The causes of metropolitan suburbanization", J Econ Perspect 7:135-147, 1993.

Mills Edwin S., Urban economics, 1972.

Munroe Daria K., "Pattern- based evaluation of peri-urban development, zoning and spatial externalities", 2006.

Muth Richard F., Cities and housing, 1969.

Muñiz - García López, “Anatomía de la dispersión en Barcelona”, UAB, febrero 2007.

Muñiz, I. and A. Galindo, "Urban form and the ecological footprint of commuting. The case of Barcelona”. Ecological Economics 55:499-514, 2005.

Muñoz Jorge, "Los Mercados de tierras rurales en Bolivia", Serie Desarrollo productivo, CEPAL, 1999. 
Solé Olle - Hortes Rico, "El impacto de la dispersión urbana sobre los costes de provisión de los servicios públicos locales. Evidencia para los municipios españoles", Universidad de Barcelona.

Torrens, Ciminari y Elsie, "Problemáticas ambientales derivadas de la expansión urbana", Depto. de Geografía, Universidad Nacional del Comahue.

Torrens, P.M., and M. Alberti. 2000. Measuring Sprawl. CASA Working Paper 27, Centre forAdvanced Spatial Analysis (CASA), University College London.

Vázquez Barquero, Antonio y Oscar Madoery, "Transformaciones globales, Instituciones y políticas de desarrollo local", 2001.

Voith Richard, " Does the Federal Tax Treatment Of Housing Affect the Pattern Of Metropolitan Development?", Federal Reserve Bank of Philadelphia Busness Review, 3-16.

Wheaton William, “A Comparative Static Analysis of Urban Spatial Structure”, Journal of economic theory 9, 223-237, 1974. 


\section{Anexo}

\begin{tabular}{|c|c|c|c|c|c|c|c|c|}
\hline $\begin{array}{l}\text { División político- } \\
\text { administrativa }\end{array}$ & $\begin{array}{c}\text { Proporción } \\
\text { Urbana } \\
\end{array}$ & $\begin{array}{c}\text { Superficie } \\
\text { Total }\end{array}$ & $\begin{array}{c}\text { Población } \\
\text { Urbana }\end{array}$ & $\begin{array}{c}\text { Salario } \\
\text { Mensual } \\
\end{array}$ & PBG & $\begin{array}{l}\text { Precio } \\
\text { Tierra } \\
\end{array}$ & $\begin{array}{c}\text { Indice } \\
\text { PP }\end{array}$ & $\begin{array}{c}\text { Parque } \\
\text { Automotor } \\
\end{array}$ \\
\hline Adolfo Alsina & 0.48 & 57.99 & 11.60 & 425.91 & 161.41 & 4.55 & 34.00 & 8.84 \\
\hline Ayacucho & 0.10 & 66.34 & 16.44 & 429.06 & 138.86 & 3.97 & 27.00 & 8.80 \\
\hline Azul & 0.54 & 64.11 & 59.35 & 441.61 & 512.09 & 7.66 & 35.00 & 27.55 \\
\hline Bahía Blanca & 4.59 & 21.83 & 283.15 & 455.65 & $2,189.75$ & 2.80 & 41.00 & 121.07 \\
\hline Balcarce & 0.43 & 40.34 & 35.15 & 429.84 & 311.81 & 11.54 & 53.00 & 18.95 \\
\hline Baradero & 1.92 & 11.04 & 24.90 & 430.00 & 203.25 & 14.67 & 57.00 & 11.40 \\
\hline Arrecifes & 0.69 & 12.10 & 24.34 & 424.39 & 193.22 & 18.75 & 64.00 & 11.14 \\
\hline Bolívar & 0.30 & 48.35 & 26.62 & 430.07 & 225.21 & 6.37 & 35.00 & 16.03 \\
\hline Bragado & 0.83 & 21.70 & 35.10 & 435.11 & 272.43 & 10.69 & 59.00 & 21.96 \\
\hline Brandsen & 2.61 & 10.90 & 18.87 & 436.29 & 143.13 & 9.00 & 32.00 & 8.80 \\
\hline Campana & 13.03 & 2.76 & 80.20 & 444.89 & $1,166.53$ & 25.46 & 40.00 & 28.54 \\
\hline Cañuelas & 3.20 & 12.55 & 36.59 & 433.70 & 234.67 & 8.82 & 32.00 & 11.53 \\
\hline Carlos Casares & 0.69 & 24.75 & 17.16 & 430.07 & 203.18 & 8.43 & 42.00 & 9.90 \\
\hline Carlos Tejedor & 0.31 & 38.37 & 8.12 & 422.52 & 110.53 & 6.37 & 47.00 & 5.01 \\
\hline Carmen de Areco & 1.36 & 10.32 & 12.01 & 422.65 & 106.15 & 17.79 & 55.00 & 5.21 \\
\hline Daireaux & 0.24 & 37.69 & 10.93 & 426.81 & 136.53 & 5.97 & 32.00 & 6.25 \\
\hline Colon & 1.59 & 9.70 & 21.40 & 430.83 & 194.35 & 18.52 & 74.00 & 8.57 \\
\hline Coronel Dorrego & 0.46 & 57.90 & 11.64 & 431.97 & 151.73 & 5.05 & 54.00 & 11.55 \\
\hline Coronel Pringles & 0.29 & 51.99 & 20.61 & 426.65 & 172.95 & 5.15 & 47.00 & 10.72 \\
\hline Coronel Suarez & 0.42 & 58.61 & 29.66 & 432.17 & 346.50 & 7.78 & 53.00 & 18.32 \\
\hline Chacabuco & 6.36 & 22.24 & 37.14 & 432.64 & 370.09 & 19.52 & 68.00 & 20.50 \\
\hline Chascomus & 0.67 & 40.08 & 34.78 & 438.90 & 338.19 & 7.14 & 32.00 & 14.66 \\
\hline Chivilcoy & 35.24 & 30.55 & 55.16 & 437.61 & 381.24 & 15.98 & 62.00 & 26.77 \\
\hline Dolores & 1.74 & 19.45 & 24.12 & 441.71 & 164.80 & 3.64 & 18.00 & 14.14 \\
\hline Esteban Echeverría & 81.88 & 2.99 & 243.19 & 426.21 & $1,316.95$ & 9.00 & - & 69.31 \\
\hline Exaltación de la Cruz & 6.81 & 6.15 & 18.15 & 438.54 & 162.63 & 17.98 & 58.00 & 7.17 \\
\hline Florencio Varela & 91.28 & 13.33 & 341.51 & 409.60 & $1,250.79$ & 21.00 & - & 47.17 \\
\hline General Alvarado & 2.30 & 15.77 & 30.29 & 432.61 & 232.09 & 11.93 & 54.00 & 11.79 \\
\hline General Alvear & 0.25 & 33.16 & 9.55 & 416.84 & 74.98 & 3.51 & 23.00 & 3.31 \\
\hline General Arenales & 1.21 & 14.34 & 10.88 & 427.68 & 147.08 & 15.69 & 69.00 & 8.59 \\
\hline General Belgrano & 0.40 & 18.09 & 13.52 & 433.87 & 107.99 & 6.85 & 37.00 & 7.43 \\
\hline Zárate & 41.99 & 8.36 & 95.06 & 433.97 & 866.34 & 19.91 & 54.00 & 30.56 \\
\hline General Juan Madariaga & 0.34 & 29.29 & 16.76 & 423.38 & 106.88 & 3.45 & 27.00 & 7.44 \\
\hline General La Madrid & 0.13 & 47.40 & 7.92 & 423.21 & 92.60 & 3.45 & 36.00 & 4.16 \\
\hline General Paz & 0.78 & 11.92 & 7.33 & 424.49 & 57.33 & 4.74 & 36.00 & 4.06 \\
\hline General Pinto & 0.39 & 25.06 & 6.15 & 425.93 & 123.05 & 12.41 & 60.00 & 3.76 \\
\hline General Pueyrredon & 10.39 & 15.04 & 551.53 & 453.20 & $4,404.79$ & 14.19 & 60.00 & 221.34 \\
\hline General Rodríguez & 18.05 & 3.26 & 63.32 & 422.44 & 382.09 & 17.73 & 47.00 & 16.25 \\
\hline General Viamonte & 0.43 & 21.37 & 13.46 & 425.13 & 137.59 & 9.68 & 55.00 & 6.47 \\
\hline General Villegas & 0.34 & 71.08 & 16.27 & 429.59 & 310.86 & 10.26 & 55.00 & 10.29 \\
\hline Adolfo Gonzales Chaves & 0.29 & 37.46 & 8.61 & 428.58 & 118.81 & 5.73 & 53.00 & 6.18 \\
\hline
\end{tabular}


Maestría en Finanzas Públicas Provinciales y Municipales - UNLP

\begin{tabular}{|c|c|c|c|c|c|c|c|c|}
\hline $\begin{array}{l}\text { División político- } \\
\text { administrativa }\end{array}$ & $\begin{array}{c}\text { Proporción } \\
\text { Urbana } \\
\end{array}$ & $\begin{array}{c}\text { Superficie } \\
\text { Total }\end{array}$ & $\begin{array}{c}\text { Población } \\
\text { Urbana }\end{array}$ & $\begin{array}{c}\text { Salario } \\
\text { Mensual } \\
\end{array}$ & PBG & $\begin{array}{l}\text { Precio } \\
\text { Tierra }\end{array}$ & $\begin{array}{c}\text { Índice } \\
\text { PP }\end{array}$ & $\begin{array}{c}\text { Parque } \\
\text { Automotor }\end{array}$ \\
\hline Guaminí & 0.30 & 45.42 & 6.81 & 426.73 & 121.02 & 4.64 & 37.00 & 6.25 \\
\hline Benito Juárez & 0.20 & 52.75 & 15.88 & 427.17 & 145.76 & 4.82 & 33.00 & 9.50 \\
\hline Junín & 1.51 & 21.28 & 82.43 & 448.03 & 762.37 & 16.66 & 57.00 & 36.44 \\
\hline La Plata & 22.32 & 8.33 & 564.87 & 480.50 & $6,024.43$ & 15.13 & 41.00 & 290.79 \\
\hline Laprida & 0.23 & 34.09 & 8.18 & 431.10 & 76.16 & 3.91 & 33.00 & 3.96 \\
\hline Las Flores & 0.26 & 32.75 & 20.72 & 427.78 & 129.61 & 3.93 & 32.00 & 9.83 \\
\hline Leandro N. Alem & 0.65 & 15.68 & 14.06 & 425.73 & 140.18 & 15.00 & 58.00 & 6.76 \\
\hline Lincoln & 0.39 & 57.80 & 29.86 & 436.42 & 329.33 & 9.10 & 48.00 & 18.21 \\
\hline Lobería & 0.25 & 46.60 & 12.20 & 420.61 & 149.09 & 11.25 & 54.00 & 8.81 \\
\hline Lobos & 2.35 & 16.82 & 26.94 & 429.56 & 193.78 & 6.81 & 42.00 & 19.01 \\
\hline Luján & 7.37 & 7.23 & 80.99 & 441.52 & 566.64 & 28.94 & 53.00 & 30.93 \\
\hline Magdalena & 0.63 & 18.14 & 9.29 & 427.28 & 93.53 & 4.61 & 32.00 & 9.43 \\
\hline Maipú & 0.32 & 25.56 & 8.87 & 430.53 & 63.73 & 3.76 & 23.00 & 5.07 \\
\hline Salliquelo & 17.09 & 18.69 & 7.52 & 428.36 & 77.41 & 20.50 & 71.00 & 13.56 \\
\hline Mar Chiquita & 0.56 & 29.64 & 14.42 & 427.24 & 119.79 & 5.45 & 30.00 & 6.14 \\
\hline Mercedes & 2.34 & 10.14 & 51.97 & 449.94 & 330.93 & 9.18 & 40.00 & 25.66 \\
\hline Monte & 1.76 & 17.93 & 13.38 & 436.11 & 116.71 & 8.05 & 43.00 & 6.19 \\
\hline Navarro & 0.52 & 15.81 & 11.56 & 418.74 & 105.48 & 6.93 & 42.00 & 9.93 \\
\hline Necochea & 1.62 & 44.67 & 82.87 & 438.27 & 651.51 & 8.75 & 54.00 & 42.12 \\
\hline Nueve de Julio & 0.60 & 41.99 & 36.89 & 438.18 & 343.98 & 9.10 & 47.00 & 20.33 \\
\hline Olavarría & 0.69 & 75.13 & 97.10 & 437.53 & 774.65 & 6.44 & 27.00 & 44.57 \\
\hline Pehuajó & 18.84 & 54.16 & 31.94 & 438.14 & 313.61 & 8.86 & 40.00 & 15.75 \\
\hline Pellegrini & 0.69 & 17.91 & 5.03 & 425.87 & 63.66 & 6.00 & 40.00 & 6.70 \\
\hline Pergamino & 10.36 & 32.78 & 85.49 & 441.46 & 768.46 & 20.58 & 61.00 & 41.50 \\
\hline Pilar & 39.15 & 3.28 & 226.65 & 443.60 & $2,121.44$ & 29.59 & 38.00 & 40.62 \\
\hline Púan & 0.50 & 62.70 & 10.12 & 433.29 & 185.29 & 2.67 & 35.00 & 10.79 \\
\hline Ramallo & 2.92 & 9.34 & 25.11 & 423.66 & 248.39 & 11.95 & 56.00 & 9.80 \\
\hline Rauch & 0.14 & 42.73 & 11.48 & 427.15 & 96.26 & 4.55 & 26.00 & 6.73 \\
\hline Rivadavia & 0.24 & 38.72 & 10.36 & 428.26 & 166.04 & 8.79 & 48.00 & 7.23 \\
\hline Rojas & 0.48 & 20.19 & 18.71 & 435.63 & 250.69 & 19.62 & 76.00 & 11.01 \\
\hline Saavedra & 0.31 & 34.84 & 15.93 & 438.27 & 199.67 & 5.02 & 49.00 & 11.24 \\
\hline Saladillo & 0.46 & 26.30 & 23.31 & 429.48 & 208.07 & 8.75 & 39.00 & 12.56 \\
\hline San Andrés de Giles & 0.61 & 11.20 & 13.94 & 426.46 & 149.29 & 16.50 & 56.00 & 7.76 \\
\hline San Antonio de Areco & 19.99 & 10.75 & 17.76 & 436.72 & 170.41 & 21.00 & 59.00 & 8.82 \\
\hline San Nicolás & 4.20 & 6.23 & 135.34 & 442.88 & 926.03 & 11.95 & 53.00 & 39.49 \\
\hline San Pedro & 1.96 & 11.62 & 47.11 & 422.51 & 296.51 & 17.93 & 55.00 & 16.44 \\
\hline San Vicente & 8.15 & 6.40 & 41.00 & 421.79 & 203.46 & 8.70 & 31.00 & 14.22 \\
\hline Tandil & 1.15 & 47.72 & 101.01 & 450.42 & 919.86 & 10.04 & 47.00 & 47.16 \\
\hline Tapalqué & 0.26 & 41.15 & 6.61 & 421.08 & 52.25 & 4.10 & 23.00 & 3.16 \\
\hline Tornquist & 0.32 & 40.78 & 6.07 & 441.76 & 130.69 & 4.78 & 46.00 & 5.92 \\
\hline Trenque Lauquen & 2.73 & 54.11 & 34.97 & 441.08 & 389.02 & 8.27 & 41.00 & 17.64 \\
\hline Tres Arroyos & 0.66 & 58.01 & 48.16 & 441.62 & 521.61 & 7.53 & 61.00 & 32.54 \\
\hline Veinticinco de Mayo & 0.50 & 46.52 & 26.60 & 425.82 & 215.89 & 7.88 & 45.00 & 14.88 \\
\hline
\end{tabular}




\begin{tabular}{|l|c|c|c|c|c|c|c|c|}
\hline $\begin{array}{l}\text { División político- } \\
\text { administrativa }\end{array}$ & $\begin{array}{c}\text { Proporción } \\
\text { Urbana }\end{array}$ & $\begin{array}{c}\text { Superficie } \\
\text { Total }\end{array}$ & $\begin{array}{c}\text { Población } \\
\text { Urbana }\end{array}$ & $\begin{array}{c}\text { Salario } \\
\text { Mensual }\end{array}$ & PBG & $\begin{array}{c}\text { Precio } \\
\text { Tierra }\end{array}$ & $\begin{array}{c}\text { Índice } \\
\text { PP }\end{array}$ & $\begin{array}{c}\text { Parque } \\
\text { Automotor }\end{array}$ \\
\hline $\begin{array}{l}\text { Coronel de Marina L. } \\
\text { Rosales }\end{array}$ & 3.50 & 10.99 & 57.30 & 451.70 & 264.29 & 4.18 & 47.00 & 23.49 \\
\hline San Cayetano & 0.25 & 29.56 & 6.76 & 426.69 & 79.23 & 6.01 & 57.00 & 4.73 \\
\hline Escobar & 22.84 & 2.67 & 173.16 & 431.94 & $1,230.82$ & 23.35 & 27.00 & 36.03 \\
\hline Hipólito Yrigoyen & 0.13 & 24.75 & 7.86 & 428.42 & 62.93 & 9.05 & 40.00 & 4.44 \\
\hline Capitán Sarmiento & 36.40 & 8.37 & 11.32 & 426.69 & 100.38 & 21.00 & 64.00 & 5.78 \\
\hline Salto & 0.35 & 7.88 & 23.82 & 431.56 & 247.20 & 7.60 & 43.00 & 4.66 \\
\hline La Costa & 30.26 & 1.78 & 60.15 & 440.67 & 552.65 & 3.60 & 13.00 & 16.28 \\
\hline Pinamar & 40.19 & 0.54 & 20.59 & 491.20 & 345.53 & 4.50 & 22.00 & 14.13 \\
\hline
\end{tabular}

Notas: el precio de la tierra se encuentra expresado en pesos por hectárea, el dato de PBG refiere a pesos corrientes, a precio de productor; mientras que la superficie total se encuentra expresada en hectáreas. El parque automotor refiere a unidades. 


\section{Índices gráficos:}

Gráfico 1: Población Urbana, provincia de Buenos Aires 9

Gráfico 2:Densidad de población, en habitantes por $\mathrm{km}^{2}$, provincia de Buenos Aires.. 10

Gráfico 3 Producto Bruto Geográfico, provincia de Buenos Aires. ............................. 12

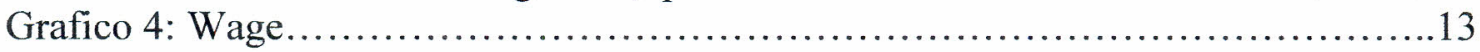

Grafico 5: Precio de la tierra......................................................... 14

Grafico 6: Índice de Productividad de la Tierra......................................... 15

Grafico 7: Parque Automotor..................................................... 16 